OPEN ACCESS

Edited by:

Yizhuo Zhang,

Sun Yat-sen University Cancer Center

(SYSUCC), China

Reviewed by:

Matteo Chinello,

Integrated University Hospital

Verona, Italy

Sebastian Dorin Asaftei,

Ospedale Città della Salute e della

Scienza, Italy

*Correspondence:

Yang $\mathrm{Li}$

liyang5@mail.sysu.edu.cn

Huang Ke

hke@mail.sysu.cn

Specialty section:

This article was submitted to

Pediatric Oncology,

a section of the journal

Frontiers in Oncology

Received: 20 November 2020 Accepted: 13 April 2021

Published: 07 May 2021

Citation:

Feng $C, L i Y, K e H$, Peng $X$, Guo $H$, Zhan L, Xiong $X$, Weng $W$, Li J and Fang J (2021)

Immune Microenvironment in Langerhans Cell Histiocytosis: Potential Prognostic Indicators.

Front. Oncol. 11:631682. doi: 10.3389/fonc.2021.631682

\section{Immune Microenvironment in Langerhans Cell Histiocytosis: Potential Prognostic Indicators}

\author{
Chuchu Feng ${ }^{1}$, Yang $\mathrm{Li}^{1 *}$, Huang Ke ${ }^{1 *}$, Xiaomin Peng ${ }^{1}$, Haixia Guo ${ }^{2}$, Liping Zhan ${ }^{1}$, \\ Xilin Xiong ${ }^{1}$, Wenjun Weng ${ }^{1}$, Jiaqiang $\mathrm{Li}^{1}$ and Jianpei Fang ${ }^{1}$ \\ ${ }^{1}$ Department of Pediatric Hematology/Oncology, Sun Yat-Sen Memorial Hospital, Sun Yat-Sen University, Guangzhou, \\ China, ${ }^{2}$ Department of Pediatrics, Nanfang Hospital, Southern Medical University, Guangzhou, China
}

In this study, the immune microenvironment in Langerhans cell histiocytosis $(\mathrm{LCH})$ was characterized to determine if immune indices are predictive of severity. Serum samples from 54 treatment-naïve patients were analyzed quantitatively for inflammatory cytokines and immunoglobulins before and after the induction of chemotherapy. The initial serum sIL-2R, TNF- $\alpha$, and IL-10 of untreated LCH patients with risk organ involvement $(\mathrm{RO}+)$ were significantly higher than those with single-system (SS) involvement. LCH patients with hematologic involvement exhibited a significantly higher sIL-2R, TNF- $\alpha$, IL-10, and IL$1 \beta$ expression, as compared to the group without involvement. SIL-2R, TNF- $\alpha$, and IL-10 were increased in patients with liver or spleen involvement. Th cells have decreased in the liver+ and spleen+ group, and Ts cells were significantly decreased in non-response group after induction chemotherapy. The serum level of immune indices represents, to some extent, the severity of the disease. Pertinent laboratory inspections can be used to improve risk stratification and guide immunotherapy.

Keywords: Langerhans cell histiocytosis, tumor immunology, children, cytokines, inflammation

\section{INTRODUCTION}

Langerhans cell histiocytosis $(\mathrm{LCH})$ is a histiocytic disorder arising from the mononuclear phagocyte system, which results in the abnormal accumulation and proliferation of LCH cells. LCH is more common in children than in adults, with the clinical manifestations varying from isolated osseous, mucocutaneous, and pulmonary involvement to multi-system (MS) involvement, such as lymph node, bone marrow, liver, spleen, gastrointestinal tract, thymus, endocrine gland, and central nervous system involvement, causing hyperplasia, fibrosis, necrosis and other pathological changes, eventually leading to organ dysfunction (1). In 2010, Badalian-very found 57\% of BRAF V600E gene positive-mutation in $61 \mathrm{LCH}$ patients (2). The disease is an inflammatory myeloid neoplasia with the characteristics of both an abnormal reactive process and a neoplastic process. Subsequent studies showed that the mutation rate of BRAF gene in $\mathrm{LCH}$ cases was $45 \%$ to $65 \%$, suggesting that the BRAF V600E gene was closely related to $\mathrm{LCH}$ incidence (3-11). De Graaf et al. found a variety of cytokines expressed in LCH lesions, such as IL-1, TGF- $\alpha$, TGF- $\beta$, TNF- $\alpha$, and TFN- $\gamma$ (11). 
Kannourakis et al. extracted and cultured monocytes from eosinophilic granulomatous tissues in patients with $\mathrm{LCH}$, and found that such monocytes could highly express IL-1, TNF- $\alpha$, GM-CSF, IL-8, and LIF-21 (12). In addition to the "cytokine storm" of local lesions, the apparent level of some inflammatory cytokines in the serum of LCH patients increased, suggesting that cytokines may be associated with the pathogenesis of LCH. At present, the etiology and pathogenesis of $\mathrm{LCH}$ remains speculative, bringing about uneven curative effect and lacking effective prognosis indicator. In the present study, the immune function of LCH children admitted to our hospital in the past 7 years was reviewed before and after induction treatment. Clarifying the immune status of $\mathrm{LCH}$ children will help provide insights into $\mathrm{LCH}$ prognosis and, ultimately, optimize and personalize therapy.

\section{METHODS}

\section{Patients}

This study was performed at the Sun Yat-sen Memorial Hospital (Guangzhou, China) between March 2013 and September 2020. A total of 54 children ( 37 males and 17 females; median age, 3.6 years; age range, 2.0 months to 12.0 years) were enrolled in this study. All patients fulfilled accepted diagnostic criteria established by the Histiocyte Society in 2009. Evaluation after the induction chemotherapy of JLSG-96/02 or Chinese Children's Histiocytic Group (CCHG)-LCH-2019 regimens was performed based on the following criteria (13): i) non active disease (NAD), no evidence of disease, Resolution of all signs or symptoms; ii) active diseasebetter (AD-B), regression of signs or symptoms, no new lesions; iii) active disease-mixed (AD-I), new lesions in one site, regression in another site; iv) active disease-stable (AD-S), persistence of signs or symptoms, no new lesions; vi) worse, progression of signs or symptoms and/or appearance of new lesions. In isolated bone disease progression is defined as appearance of new bone lesions or lesions in other organs. Risk organs include the hematologic system, the spleen and the liver. All methods were carried out in accordance with relevant guidelines and regulations. All peripheral blood samples were obtained with written informed consent from the legal guardian of patients. The study was approved by the ethics committee at Sun Yat-sen Memorial Hospital.

\section{Cytokine, Immunoglobulin, and Lymphocyte Subset Measurement}

Prior to treatment, and 2 weeks after the initial induction of chemotherapy, the serum levels of the cytokines IL-8, IL-6, IL-10, IL-1 $\beta$, and sIL-2R were measured using the IMMULITE-1000 Immunoassay System (Siemens Healthineers, Erlangen, Germany) while the immunoglobulins IgA, IgG, IgM and IgE were detected by the BN II system (Siemens Healthineers). Lymphocyte subsets in the peripheral blood, including T, B, natural killer, cytokineinduced killer, $\mathrm{T}$ helper (Th), suppressor $\mathrm{T}$ (Ts), Th/Ts, and regulatory $\mathrm{T}$ cells (Treg) were tested using a FACSCanto ${ }^{\mathrm{TM}}$ II flow cytometer (Beckman Coulter, Inc., Brea, CA, USA), using a BD Multitest ${ }^{\mathrm{TM}}$ 6-color TBNK kit and DIVA software.

\section{Statistical Analysis}

Data were statistically analyzed using SPSS software (version 21.0). The continuous variables were expressed as the mean \pm standard deviation and the count variables were expressed in frequency/rate. Original data of inflammatory factors IL-10 and IL-1 $\beta$ were expressed as $<5 \mathrm{pg} / \mathrm{ml}$, which were transformed into qualitative variables in the correlation analysis. The non-paired $t$ and Kruskal-Wallis $\mathrm{H}$ tests were used to assess the statistical significance between the groups. To compare qualitative data we used the Fisher's exact test. $\mathrm{P}<0.05$ was considered to indicate a statistically significant difference.

\section{RESULTS}

Patient Characteristics (Table 1).

\section{Analysis of Immune Indices and Clinical Types}

A total of 17 patients had multifocal single system disease (SS), 15 patients had multiple system disease without risk organ involvement (RO-), and the remaining 22 patients had risk organ involvement ( $\mathrm{RO}+)$. Among the inflammatory cytokines, as shown in Figure 1, significantly higher serum levels of sIL-2R $(2244.2 \pm 2790.9$ vs $595.4 \pm 366.7 \mu / \mathrm{ml})$, TNF- $\alpha(31.0 \pm 24.0$ vs $11.8 \pm 4.6 \mathrm{pg} / \mathrm{ml}$ ), and IL-10 were observed in the RO+ group, as compared to the SS group. The percentages of $\mathrm{T}$ cells in peripheral blood were obviously lower in the $\mathrm{RO}+$ group than RO-, while B cells obviously increased (Figure 2). No statistical significance was identified in immunoglobulin (Table 2).

Next, patients were divided into the groups depending on the type of organ involvement. As shown in Figure 3, patients with hematologic involvement exhibited a significantly higher sIL-2R, TNF- $\alpha$, IL-10, and IL- $1 \beta$ expression, as compared to the group without involvement. sIL-2R, TNF- $\alpha$, and IL-10 were increased

TABLE 1 | Clinical characteristics of 54 children with LCH.

\begin{tabular}{lc}
\hline & No. of patients \\
\hline Gender & Gender \\
Male & 37 \\
Female & 17 \\
Age at diagnosis (yrs) & \\
Median & 3.6 \\
Disease classification & \\
Multifocal single system (SS) & 17 \\
Multiple system without risk organ involvement (MS-RO-) & 15 \\
Multiple system with risk organ involvement (MS-RO+) & 22 \\
Risk organ involvement & \\
Liver & 18 \\
Spleen & 6 \\
Hematologic & 3 \\
Response at week 6 & \\
NAD & 9 \\
AD-B & 33 \\
AD-l & 1 \\
AD-S & 8 \\
Worse & 3 \\
&
\end{tabular}



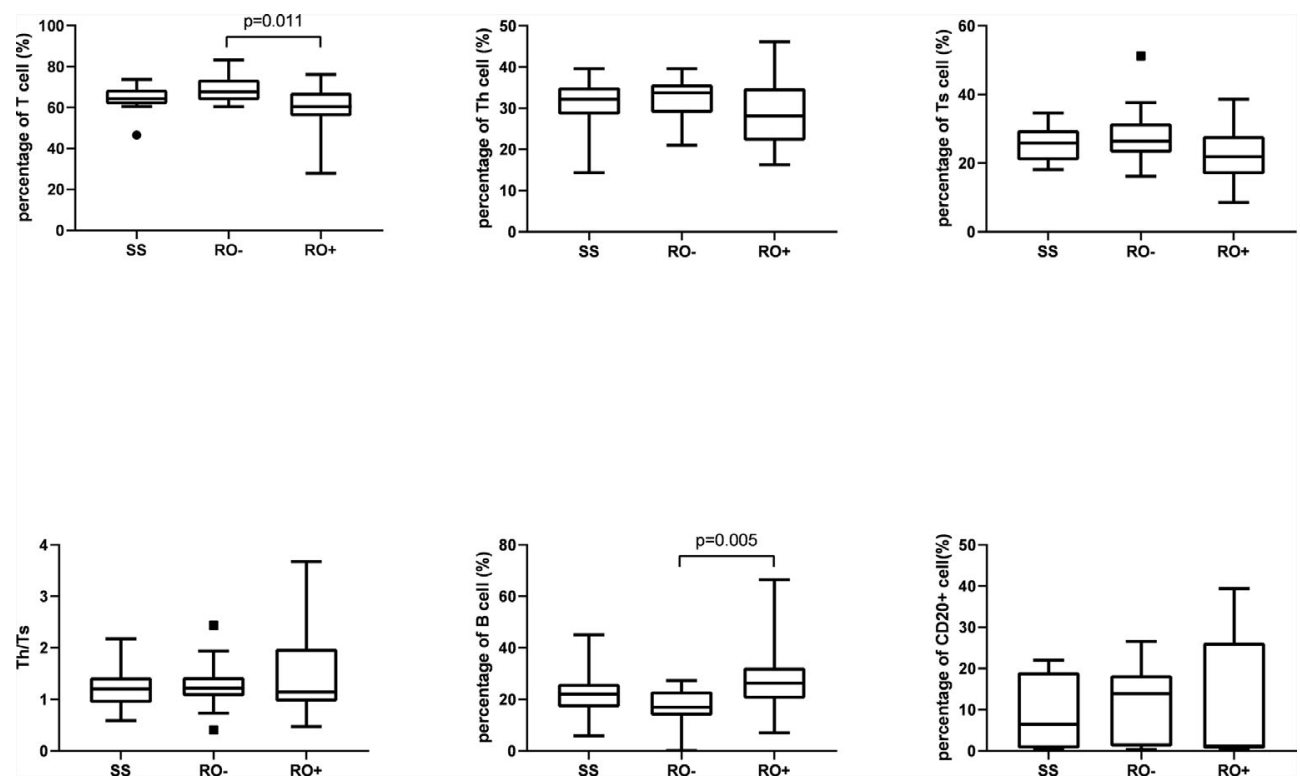

FIGURE 1 | The serum level of inflammatory cytokines in disease classification.
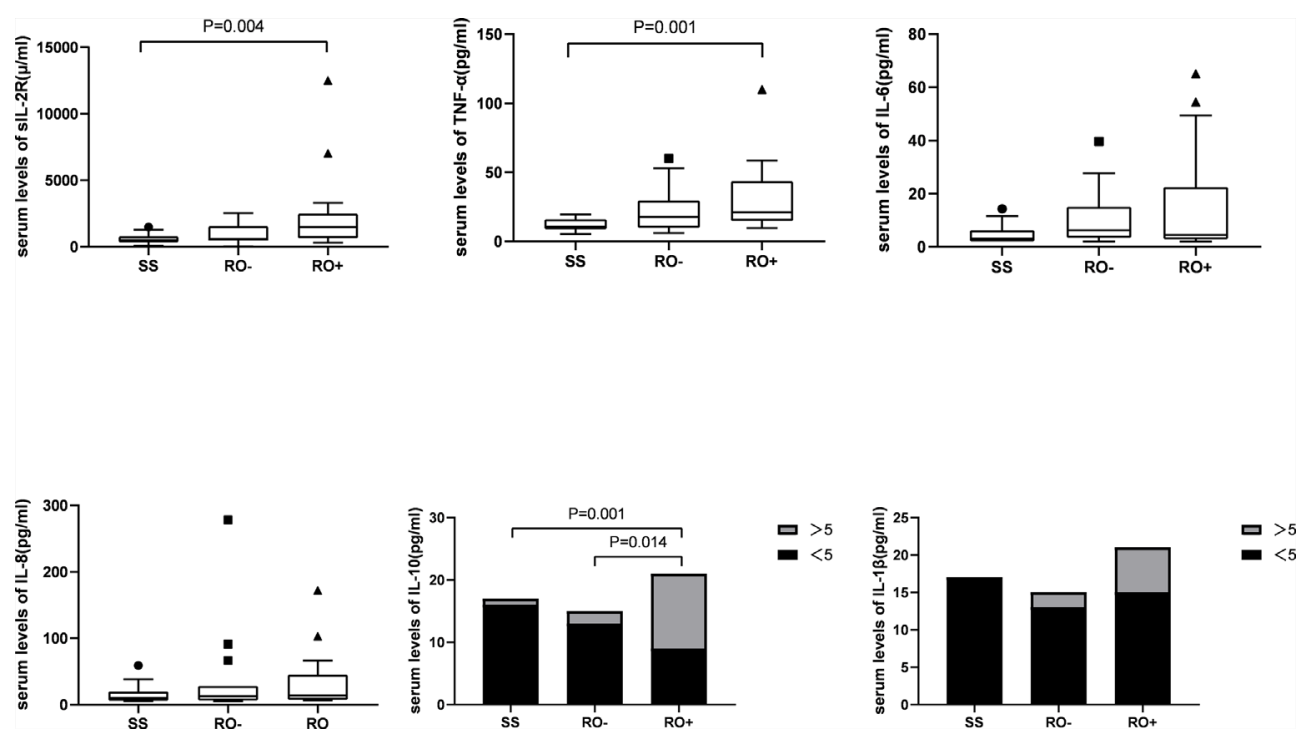

FIGURE 2 | The lymphocyte subset in disease classification.

in patients with liver or spleen involvement. The percentage of $\mathrm{T}$ and Th cells were significantly lower in the spleen+ group, but B cells subset increased by contrast. Similarly, the percentage of Th cells and Th/Ts ratio has decreased in the liver+ group (Table 3).

\section{Analysis of Immune Indices Before and After Induction Chemotherapy}

In order to clarify whether the change in immune indices can be used as a marker of efficacy, serum levels of cytokines, immunoglobulins and lymphocyte subsets were measured prior to treatment. All cases underwent initial chemotherapy of the JLSG-96/ 02 or CCHG-LCH-2019 regimen, based on disease status. Following the induction of chemotherapy, Ts cells were significantly decreased in non-response group. However, no significant changes were observed in cytokine and immunoglobulin between the response $(\mathrm{NAD}+\mathrm{AD}-\mathrm{B}+\mathrm{AD}-\mathrm{I})$ and non-response $(\mathrm{AD}-\mathrm{S}+\mathrm{Worse})$ groups (Table 4). Similarly, no significant changes were observed when we further divided the data into SS, MS, RO- and RO+ sets. 
TABLE 2 | Immunoglobulin in different disease classification.

\begin{tabular}{|c|c|c|c|c|}
\hline Immune indices & \multicolumn{4}{|c|}{ Disease classification } \\
\hline $\lg A(g / l)$ & $2.0 \pm 1.0$ & $1.2 \pm 0.7$ & $1.4 \pm 1.0$ & 0.052 \\
\hline $\operatorname{lgM}(g / /)$ & $1.5 \pm 0.5$ & $1.3 \pm 0.5$ & $1.4 \pm 0.7$ & 0.729 \\
\hline $\lg \mathrm{E}(\mathrm{IU} / \mathrm{ml})$ & $543.4 \pm 1275.1$ & $166.3 \pm 284.0$ & $152.6 \pm 226.8$ & 0.466 \\
\hline
\end{tabular}
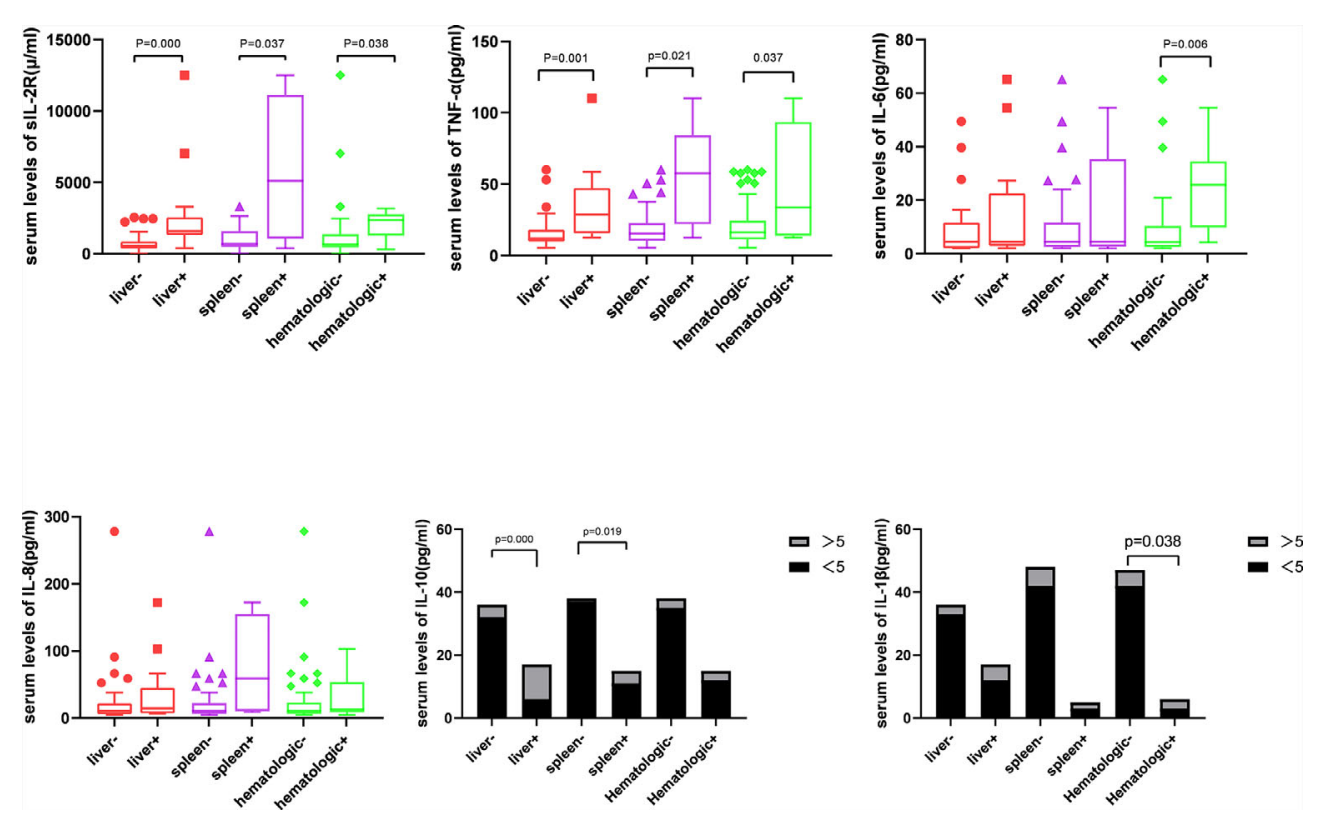

FIGURE 3 | Analysis of inflammatory cytokines and affected organs.

TABLE 3 | Lymphocyte subset in different affected organs.

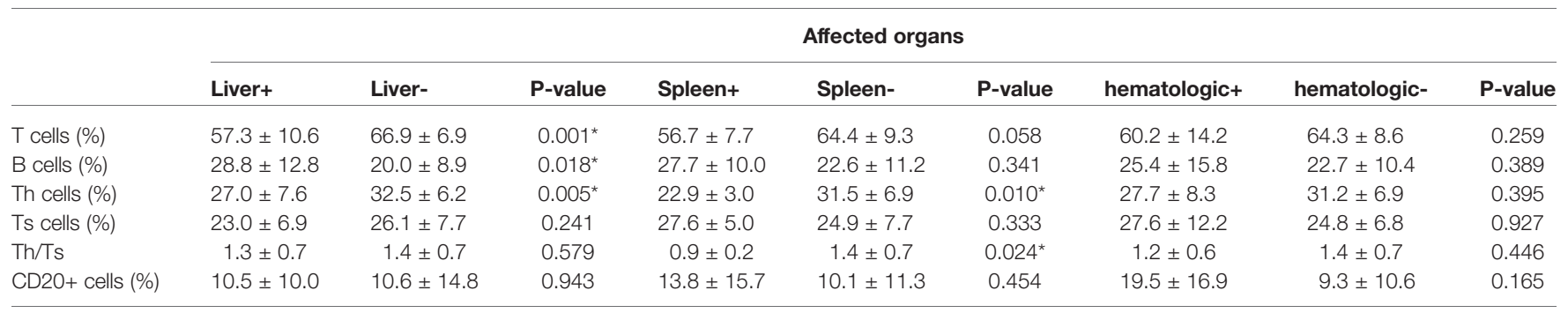

*Statistical difference between the affected organs groups $(P<0.05)$.

Th, Thelper; Ts, suppressor T.

\section{DISCUSSION}

$\mathrm{LCH}$ is a heterogeneous disease and it can affect from single, localized lesions to multiple systems/organs, including risk organs. The prognosis of different subtypes of LCH is highly variable. Partial cases with a solitary bone lesion can be cured by curettage, and children with skin-isolated LCH usually require no specific therapy, as spontaneous healing may occur. MS-LCH with risk organ involvement, such as liver and hematopoietic system, has a poor response to therapy, resulting in a particularly dismal prognosis (14). To date, the pathogenesis of $\mathrm{LCH}$ remains unclear. In recent years, it was found that the MAPK pathway is involved in the pathogenesis of $\mathrm{LCH}$, with the mutation of more than half of BRAF, $20 \%$ of MAP2K1 and rare ARAF, MAP3K1 (2, 15). However, studies have shown that cytokines are essential for local infiltration and metastasis of LCH cells $(16,17)$. De Graaf et al. found a variety of cytokines in LCH lesions, such as IL-1, TGF- $\alpha$, TGF- $\beta$, GM-CSF, TNF- $\alpha$, and TFN- $\gamma$ (11). Kannourakis 
TABLE 4 | Comparison of immune indices before and after induction chemotherapy.

\begin{tabular}{|c|c|c|c|}
\hline Immune index rangeability (After-before) & Response & Non-response & P-value \\
\hline$\Delta \mathrm{slL}-2 \mathrm{R}(\mu / \mathrm{ml})$ & $50.9 \pm 609.6$ & $13.3 \pm 879.0$ & 0.870 \\
\hline$\Delta \mathrm{lL}-6(\mathrm{pg} / \mathrm{ml})$ & $-2.4 \pm 18.4$ & $4.3 \pm 20.2$ & 0.299 \\
\hline$\Delta \mathrm{TNF}-\alpha(\mathrm{pg} / \mathrm{ml})$ & $18.6 \pm 66.2$ & $2.9 \pm 12.8$ & 0.438 \\
\hline$\Delta \mathrm{lL}-8(\mathrm{pg} / \mathrm{ml})$ & $-0.2 \pm 101.0$ & $-31.8 \pm 134.4$ & 0.389 \\
\hline$\Delta \lg A(g / l)$ & $0.2 \pm 0.7$ & $0.2 \pm 0.3$ & 0.963 \\
\hline$\Delta \operatorname{lgG}(g / l)$ & $1.8 \pm 4.3$ & $1.3 \pm 2.4$ & 0.677 \\
\hline$\Delta \operatorname{lgM}(g / l)$ & $0.3 \pm 0.8$ & $0.5 \pm 0.3$ & 0.471 \\
\hline$\Delta \operatorname{lgE}(\mathrm{IU} / \mathrm{ml})$ & $-13.0 \pm 473.2$ & $77.3 \pm 158.3$ & 0.539 \\
\hline$\Delta \mathrm{T}$ cell $(\%)$ & $-3.4 \pm 23.3$ & $-20.4 \pm 17.1$ & $0.036^{\star}$ \\
\hline$\Delta \mathrm{B}$ cell $(\%)$ & $2.1 \pm 17.5$ & $9.0 \pm 11.7$ & 0.150 \\
\hline$\Delta \mathrm{NK}$ cell (\%) & $-0.9 \pm 8.2$ & $0.9 \pm 8.2$ & 0.531 \\
\hline$\Delta$ Th cell (\%) & $-1.7 \pm 13.4$ & $-5.9 \pm 17.6$ & 0.384 \\
\hline$\Delta \mathrm{Ts}$ cell $(\%)$ & $-0.2 \pm 12.8$ & $-9.6 \pm 12.3$ & $0.035^{\star}$ \\
\hline$\Delta \mathrm{Th} / \mathrm{Ts}$ & $0.5 \pm 3.3$ & $-0.03 \pm 1.0$ & 0.347 \\
\hline$\Delta \mathrm{CD} 20+$ cell $(\%)$ & $2.7 \pm 16.9$ & $13.2 \pm 10.5$ & 0.153 \\
\hline
\end{tabular}

Th, Thelper; Ts, suppressor T.

*Statistical difference between the Affected organs groups $(P<0.05)$.

et al. extracted and cultured monocytes from eosinophilic granulomatous tissues in patients with $\mathrm{LCH}$, and found that such monocytes could produce a large number of IL-1, TNF- $\alpha$, GM-CSF, IL-8, and LIF-21 (12). Pathologically, one of the cardinal manifestations of $\mathrm{LCH}$ is the accumulation of pathologic $\mathrm{LCH}$ cells in target tissues, surrounding by the varying degrees of lymphocyte infiltration, such as $\mathrm{T}$ cells, macrophages, eosinophils, and B cells, as well as multinucleated giant cells. Egeler used immunohistochemical techniques to detect LCH and $\mathrm{T}$ cells, macrophages and eosinophils in 14 children with $\mathrm{LCH}$; it was found that cytokines mainly originated from $\mathrm{LCH}$ and $\mathrm{T}$ cells (18). On the other hand, $\mathrm{LCH}$ is seen as a result of a misguided differentiation of myeloid dendritic cell (DC) precursors originating from multiple hematopoietic stem cells, whose differentiation, maturation and migration are regulated by diverse cytokines (19). For example, Cumberbatch found that DCs were significantly concentrated in the lymph nodes of mice following a subcutaneous injection of TNF- $\alpha$. However, this phenomenon did not occur after injecting the same dose of TNF- $\alpha$ directly into the lymph nodes, suggesting that TNF- $\alpha$ may contribute to the migration of DC/LC lineage cells (20).

In 1994, Kannourakis reported elevated peripheral blood levels of GM-CSF and IL-3 in MS-LCH patients, recognizing that cytokines in LCH lesions were likely to be released to the circulation (12). Our results demonstrated that the serum levels of sIL-2R, TNF- $\alpha$, and IL-10 in the MS-LCH patients with RO+ were significantly higher than SS-LCH patients. In particular, sIL$2 \mathrm{R}, \mathrm{TNF}-\alpha$, and IL-10 were noticeably increased in patients with liver spleen and hematologic involvement. This indicated that serum levels of sIL-2R, TNF- $\alpha$, and IL-10 may reflect the severity of the disease in LCH to a certain extent. Morimoto's study, which found the serum levels of 9 humoral factors, including IL-2R, IL-8, IL-18, and M-CSF, substantially higher in patients with MS-LCH than in those with SS-LCH (21). sIL-2R consists of three chains; $\alpha$ (also termed IL-2R $\alpha, \mathrm{CD} 25$, or Tac antigen), $\beta$ (also termed IL$2 \mathrm{R} \beta$ or CD122), and $\gamma$ (also termed IL-2R $\gamma$ or CD132). The principal functions of IL-2R $\alpha$ are to bind with IL-2 and promote optimal IL-2 signaling through its association with the IL-2R $\beta$ and IL-2R $\gamma$ chains, while inhibiting the clonal proliferation of activated T cells. IL-2, IL-2R $\beta$, and IL-2R $\gamma$ are rapidly degraded, but IL- $2 \mathrm{R} \alpha$ is recycled to the cell surface. Thus, the available concentration of the soluble form of IL-2R ( $I L 2 R \alpha)$ determines the tempo, magnitude and extent of $\mathrm{T}$ cell immune responses. TNF- $\alpha$ is mainly produced by activated macrophages with a wide range of biological functions, including the induction of inflammation, anti-tumor effect, activation of $\mathrm{T}$ cells, and mediated immune response. IL-2R and TNF- $\alpha$ have been reported to play an important role in inducing the generation and maturation of LCs in vitro (22). It has also been found that serum sIL-2R and TNF- $\alpha$ are significantly elevated in LCH patients $(23,24)$. IL-10 could bind with IL-10 receptors on tumor cells to activate STAT3, which thus promotes the proliferation of tumor cells via the activation of cell cycle-related proteins $(25,26)$. It has been hypothesized that IL-10 may play a role in the assessment of $\mathrm{LCH}$, since a study reported an increased expression of IL-10 in LCH lesions (27).

Cytokine elevation indicates a disturbance in cellular immunity. The number of $\mathrm{T}$ cells in an active state in $\mathrm{LCH}$ lesions was second only to the number of LCH cells (27). Treg cells were also found to be increased in the peripheral blood of $\mathrm{LCH}$ patients $(28,29)$. Our findings have shown that the percentage of Th cells and Th/Ts ratio in the peripheral blood of $\mathrm{LCH}$ patients with liver or spleen involvement was lower than those without involvement. After that, the level of Ts cell dropped during the induction treatment in non-response group. Suppressor T cell (Ts), also call regulatory cells (Tregs), were the second most common type of infiltrating immune cell in LCH tissue (30). Ts could inhibit immune responses against LCH cells, which lead to increasing survival of LCH cells, granuloma maintenance, and dissemination (28). It seems to reflect that the abnormal regulation of $\mathrm{T}$ lymphocyte may affect the disease progression.

The present study failed to reflect the effects of the changes in immune indicators on the assessment of efficacy. Some clinical observation showed that the ratio of serum TNF- $\alpha$ (23), IL-2R, 
RANKL, OPG, and SRANKL/OPG (24) significantly decreased following chemotherapy. Patients with IL-18 serum levels of $>500 \mathrm{pg} / \mathrm{ml}$ were insensitive to JLSG treatment (21). To date, there have been a number of studies with similar results, at home and abroad, but it is necessary to explore and confirm the underlying mechanisms by a large-scale, multicenter trial. Therefore, changes in serum cytokines may be used as a marker of the curative effect of clinical treatment, but whether it is a sensitive and specific marker requires further research.

Children with LCH often present with MS damage at onset and frequently involved risk organs. These cases are characterized by a long disease course, low cure rate and easy recurrence. Increased understanding of the pathogenesis and pathological changes of different clinical types of LCH will help optimize and personalize therapy, which can, in turn, improve the curative effect. Initial reports have indicated that immunocyte and cytokine immunoregulatory disorders might be linked to the occurrence, and development of LCH. Pertinent laboratory inspections can be used as prognostic indices for children with $\mathrm{LCH}$, to improve risk-stratification and guide immunotherapy. Besides, the short assessment time, the change of the clinical classification and complications, such as infections during treatment may also affect the results. It may be possible to collect immune indicators of patients during the 12 weeks of induction and maintenance treatment in a follow-up study.

\section{REFERENCES}

1. Morimoto A, Oh Y, Shioda Y, Kudo K, Imamura T. Recent Advances in Langerhans Cell Histiocytosis. Pediatr Int (2014) 56:451-61. doi: 10.1111/ ped. 12380

2. Badalian-Very G, Vergilio JA, Degar BA, MacConaill LE, Brandner B, Calicchio ML, et al. Recurrent BRAF Mutations in Langerhans Cell Histiocytosis. Blood (2010) 116:1919-23. doi: 10.1182/blood-2010-04-279083

3. Haroche J, Charlotte F, Arnaud L, von Deimling A, Helias-Rodzewicz Z, Hervier B, et al. High Prevalence of BRAF V600E Mutations in ErdheimChester Disease But Not in Other non-Langerhans Cell Histiocytoses. Blood (2012) 120:2700-3. doi: 10.1182/blood-2012-05-430140

4. Sahm F, Capper D, Preusser M, Meyer J, Stenzinger A, Lasitschka F, et al. BRAFV600E Mutant Protein is Expressed in Cells of Variable Maturation in Langerhans Cell Histiocytosis. Blood (2012) 120:e28-34. doi: 10.1182/blood2012-06-429597

5. Satoh T, Smith A, Sarde A, Lu HC, Mian S, Trouillet C, et al. B-RAF Mutant Alleles Associated With Langerhans Cell Histiocytosis, a Granulomatous Pediatric Disease. PLoS One (2012) 7:e33891. doi: 10.1371/journal.pone.0033891

6. Bubolz AM, Weissinger SE, Stenzinger A, Arndt A, Steinestel K, Bruderlein S, et al. Potential Clinical Implications of BRAF Mutations in Histiocytic Proliferations. Oncotarget (2014) 5:4060-70. doi: 10.18632/oncotarget.2061

7. Chilosi M, Facchetti F, Calio A, Zamo A, Brunelli M, Martignoni G, et al. Oncogene-Induced Senescence Distinguishes Indolent From Aggressive Forms of Pulmonary and non-Pulmonary Langerhans Cell Histiocytosis. Leuk Lymphoma (2014) 55:2620-6. doi: 10.3109/10428194.2014.887713

8. Mehes G, Irsai G, Bedekovics J, Beke L, Fazakas F, Rozsa T, et al. Activating BRAF V600E Mutation in Aggressive Pediatric Langerhans Cell Histiocytosis: Demonstration by Allele-Specific PCR/direct Sequencing and Immunohistochemistry. Am J Surg Pathol (2014) 38:1644-8. doi: 10.1097/ PAS.0000000000000304

9. Roden AC, Hu X, Kip S, Parrilla Castellar ER, Rumilla KM, Vrana JA, et al. Braf V600E Expression in Langerhans Cell Histiocytosis: Clinical and Immunohistochemical Study on 25 Pulmonary and 54 Extrapulmonary Cases. Am J Surg Pathol (2014) 38:548-51. doi: 10.1097/PAS.000 0000000000129

\section{DATA AVAILABILITY STATEMENT}

The original contributions presented in the study are included in the article/supplementary mterial. Further inquiries can be directed to the corresponding authors.

\section{ETHICS STATEMENT}

The studies involving human participants were reviewed and approved by Sun Yat-Sen Memorial Hospital. Written informed consent to participate in this study was provided by the participants' legal guardian/next of kin.

\section{AUTHOR CONTRIBUTIONS}

YL: conceptualization, writing-review and editing and supervision. HK: conceptualization, methodology, and supervision. CF: formal analysis, writing-original draft, and visualization. XP: data curation. HG: validation. LZ: data curation. XX: formal analysis. WW: supervision. JL: data curation. JF: supervision. All authors contributed to the article and approved the submitted version.

10. Berres ML, Lim KP, Peters T, Price J, Takizawa H, Salmon H, et al. BrafV600E Expression in Precursor Versus Differentiated Dendritic Cells Defines Clinically Distinct LCH Risk Groups. J Exp Med (2015) 212:281. doi: 10.1084/ jem.2013097701202015c

11. de Graaf JH, Tamminga RY, Dam-Meiring A, Kamps WA, Timens W. The Presence of Cytokines in Langerhans' Cell Histiocytosis. J Pathol (1996) 180:400-6. doi: 10.1002/(SICI)1096-9896(199612)180:4<400::AID PATH701>3.0.CO;2-W

12. Kannourakis G, Abbas A. The Role of Cytokines in the Pathogenesis of Langerhans Cell Histiocytosis. Br J Cancer Suppl (1994) 23:S37-40.

13. Morimoto A, Shioda Y, Imamura T, Kudo K, Kawaguchi H, Sakashita K, et al. Intensified and Prolonged Therapy Comprising Cytarabine, Vincristine and Prednisolone Improves Outcome in Patients With Multisystem Langerhans Cell Histiocytosis: Results of the Japan Langerhans Cell Histiocytosis Study Group02 Protocol Study. Int J Hematol (2016) 104:99-109. doi: 10.1007/s12185-0161993-3

14. Arico M. Langerhans Cell Histiocytosis in Children: From the Bench to Bedside for an Updated Therapy. Br J Haematol (2016) 173:663-70. doi: 10.1111/bjh.13955

15. Kolenova A, Schwentner R, Jug G, Simonitsch-Klupp I, Kornauth C, Plank L, et al. Targeted Inhibition of the MAPK Pathway: Emerging Salvage Option for Progressive Life-Threatening Multisystem LCH. Blood Adv (2017) 1:352-6. doi: 10.1182/bloodadvances.2016003533

16. Garabedian L, Struyf S, Opdenakker G, Sozzani S, Van Damme J, Laureys G. Langerhans Cell Histiocytosis: A Cytokine/Chemokine-Mediated Disorder? Eur Cytokine Netw (2011) 22:148-53. doi: 10.1684/ecn.2011.0290

17. Berres ML, Allen CE, Merad M. Pathological Consequence of Misguided Dendritic Cell Differentiation in Histiocytic Diseases. Adv Immunol (2013) 120:127-61. doi: 10.1016/B978-0-12-417028-5.00005-3

18. Egeler RM, Favara BE, van Meurs M, Laman JD, Claassen E. Differential In Situ Cytokine Profiles of Langerhans-like Cells and T Cells in Langerhans Cell Histiocytosis: Abundant Expression of Cytokines Relevant to Disease and Treatment. Blood (1999) 94:4195-201.

19. Rizzo FM, Cives M, Simone V, Silvestris F. New Insights Into the Molecular Pathogenesis of Langerhans Cell Histiocytosis. Oncologist (2014) 19:151-63. doi: 10.1634/theoncologist.2013-0341 
20. Cumberbatch M, Kimber I. Dermal Tumour Necrosis Factor-Alpha Induces Dendritic Cell Migration to Draining Lymph Nodes, and Possibly Provides One Stimulus for Langerhans' Cell Migration. Immunology (1992) 75:257-63.

21. Morimoto A, Oh Y, Nakamura S, Shioda Y, Hayase T, Imamura T, et al. Inflammatory Serum Cytokines and Chemokines Increase Associated With the Disease Extent in Pediatric Langerhans Cell Histiocytosis. Cytokine (2017) 97:73-9. doi: 10.1016/j.cyto.2017.05.026

22. Zou GM, Tam YK. Cytokines in the Generation and Maturation of Dendritic Cells: Recent Advances. Eur Cytokine Netw (2002) 13:186-99.

23. Rosso DA, Ripoli MF, Roy A, Diez RA, Zelazko ME, Braier JL. Serum Levels of Interleukin-1 Receptor Antagonist and Tumor Necrosis FactorAlpha are Elevated in Children With Langerhans Cell Histiocytosis. $J$ Pediatr Hematol Oncol (2003) 25:480-3. doi: 10.1097/00043426200306000-00010

24. Ishii R, Morimoto A, Ikushima S, Sugimoto T, Asami K, Bessho F, et al. High Serum Values of Soluble CD154, IL-2 Receptor, RANKL and Osteoprotegerin in Langerhans Cell Histiocytosis. Pediatr Blood Cancer (2006) 47:194-9. doi: $10.1002 /$ pbc.20595

25. Li L, Shaw PE. Autocrine-Mediated Activation of STAT3 Correlates With Cell Proliferation in Breast Carcinoma Lines. J Biol Chem (2002) 277:17397-405. doi: 10.1074/jbc.M109962200

26. Chen CL, Cen L, Kohout J, Hutzen B, Chan C, Hsieh FC, et al. Signal Transducer and Activator of Transcription 3 Activation is Associated With Bladder Cancer Cell Growth and Survival. Mol Cancer (2008) 7:78. doi: 10.1186/1476-4598-7-78

27. Quispel WT, Stegehuis-Kamp JA, Santos SJ, Egeler RM, van Halteren AG. Activated Conventional T-Cells Are Present in Langerhans Cell Histiocytosis
Lesions Despite the Presence of Immune Suppressive Cytokines. J Interferon Cytokine Res (2015) 35:831-9. doi: 10.1089/jir.2014.0190

28. Senechal B, Elain G, Jeziorski E, Grondin V, Patey-Mariaud de Serre N, Jaubert F, et al. Expansion of Regulatory T Cells in Patients With Langerhans Cell Histiocytosis. PLoS Med (2007) 4:e253. doi: 10.1371/ journal.pmed.0040253

29. Tong C, Jia X, Jia Y, He Y. Langerhans Cell Histiocytosis in Chinese Adults: Absence of BRAF Mutations and Increased FOXP3(+) Regulatory T Cells. Int J Clin Exp Pathol (2014) 7:3166-73.

30. Paredes SEY, Almeida LY, Trevisan GL, Polanco XBJ, Silveira HA, Vilela Silva E, et al. Immunohistochemical Characterization of Immune Cell Infiltration in Paediatric and Adult Langerhans Cell Histiocytosis. Scand J Immunol (2020) 92:e12950. doi: 10.1111/sji.12950

Conflict of Interest: The authors declare that the research was conducted in the absence of any commercial or financial relationships that could be construed as a potential conflict of interest.

The handling editor declared a shared affiliation, though no other collaboration, with several of the authors CF, YL, HK, XP, HG, LZ, XX, WW, JL, and JF.

Copyright (๑) 2021 Feng, Li, Ke, Peng, Guo, Zhan, Xiong, Weng, Li and Fang. This is an open-access article distributed under the terms of the Creative Commons Attribution License (CC BY). The use, distribution or reproduction in other forums is permitted, provided the original author(s) and the copyright owner(s) are credited and that the original publication in this journal is cited, in accordance with accepted academic practice. No use, distribution or reproduction is permitted which does not comply with these terms. 